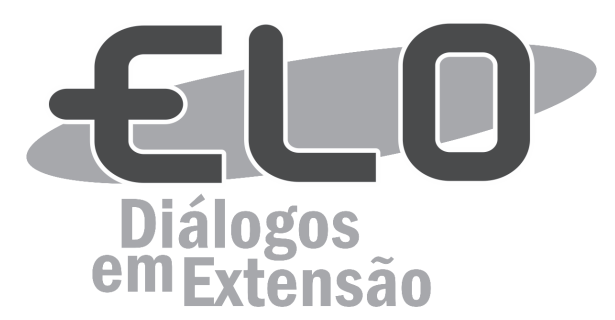

\title{
Outras janelas para o mundo - A leitura e a escrita como arte e como prática libertadora
}

\author{
Patrícia Muratori de Lima e Silva Negrão ${ }^{1}$, Maria de Fátima dos Santos ${ }^{2}$
}

\begin{abstract}
Resumo: Este trabalho é fruto de uma atividade de Extensão (PIBEX) da Universidade Federal de Viçosa (UFV) e teve como meta promover nas crianças e adolescentes o desenvolvimento do hábito da leitura, despertar o interesse para as produções artísticas, a criatividade e o interesse pela produção de texto oral e escrito com atividades voltadas ao incentivo tanto à leitura quan to à escrita como forma de estimular a reflexão, a capacidade criadora e transformadora da sociedade. Também buscou-se estudar a realidade de vida desses jovens e a influência prejudicial que ela pudesse exercer no interesse, na capacidade e na habilidade de leitura e da escrita. A partir disso, buscou-se intervir, buscando minimizar esses efeitos negativos por meio da troca de saberes sistematizados, acadêmicos e populares, da prestação de serviços e da difusão cultural, a fim de sensibilizar crianças e jovens de seus papéis como cidadãos para que possam atuar na sociedade na condição de protagonistas.
\end{abstract}

Palavras-chave: Leitura. Escrita. Criatividade. Autonomia. Intervenção social.

Área Temática: Educação. Cultura.

\section{Other windows to the world - reading and writing as an art and as a practice of liberation}

Abstract: This work is the result of an extension activity (PIBEX) at Federal University of Viçosa (UFV), it was aimed to develop in children and adolescents the habit of reading, awakening their interest in artistic productions, creativity and interest in production of oral and written text with activities aimed at encouraging both reading and writing as a way to stimulate reflection, what it is creative society capacity and transforming. It was also sought to study these young people's life realityand the harmful influence it could exert in the interest, in the reading and writing abilities. From this, we sought to intervene in order to minimize these negative effects through the systematized, academic and popular exchange knowledge, the provision of services and cultural diffusion in order to sensitize children and youth in their roles as citizens so that they can act in society on condition of protagonists.

Keywords: Reading. Writing. Creativity. Autonomy. Social intervention.

\section{Otras ventanas para el mundo - La lectura y la escritura como arte y como práctica liberadora}

Resumen: Este trabajo es el resultado de una extensión de la actividad (PIBEX) de la Universidad Federal de Viçosa (UFV) y tenía como objetivo promover en los niños y adolescentes a desarrollar el hábito de la lectura, despertar el interés por la producción artística, la creatividad y el interés en producción de textos orales y escritos con actividades dirigidas a fomentar tanto la lectura como la escritura como una forma de estimular la reflexión, la capacidad creativa y la transformación de la sociedad. También trató de estudiar la realidad de la vida de estos jóvenes y la influencia perjudicial que pudiera ejercer sobre el interés, la capacidad

\footnotetext{
${ }^{1}$ Técnica em Assuntos Educacionais da Universidade Federal de Viçosa (DEX/UFV) e Coordenadora do Projeto. Rua Hélio Stanciola, 30. Bairro de Fátima - Viçosa/ MG, Brasil (31) 9 87790207. E-mail: patricia.negrao@ufv.br

${ }^{2}$ Graduanda do Curso de Licenciatura em Educação do Campo da Universidade Federal de Viçosa (DEX/UFV) e bolsista do Projeto. Viçosa/MG, Brasil. fatimasantos40@yahoo.com.br
} 
y las habilidades de lectura y escritura $y$, A partir de esto, hemos tratado de intervenir con el fin de minimizar estos efectos negativos mediante el intercambio de conocimiento sistematizado, académico y popular, la prestación de servicios y la difusión cultural con el fin de sensibilizar a los niños y jóvenes en sus papeles como ciudadanos para que puedan actuar en la sociedad bajo condición de protagonistas.

Palabras clave: Lectura. Escribiendo. La creatividad. Autonomía. La intervención social.

\section{Introdução}

Mais urgente do que aprender a ler e a escrever textos, é aprender a ler o mundo, já dizia Paulo Freire. Com isso, o célebre pensador no campo da educação, queria deixar claro que o ato de ler o mundo não corresponde a uma manipulação mecânica de palavras, mas à compreensão da relação dialógica existente entre realidade e linguagem. Nessa perspectiva, mais do que codificar ou decodificar uma mensagem, aprender a ler e a escrever é ser capaz atribuir sentido e de agir socialmente por meio da linguagem.

Porém, Panet (1998) ressalta que não é bastante o estudante saber ler, se não encontra o que ler, onde e o tipo de atividades da biblioteca que o desperte para o desejo de continuar a ler. Também afirma que não é bastante exigir que o estudante escreva, se não foi devidamente preparado para isso e que é importante que essa criança, esse jovem, ou mesmo esse adulto, entenda o valor real da leitura e da escrita como forma de exercício da cidadania.

Sendo assim, e por acreditar que o leitor, ao penetrar nos horizontes do texto, expande suas experiências e participa da transformação da cultura, no ano de 2015, por meio do Programa Institucional de Bolsas de Extensão (PIBEX) da Universidade Federal de Viçosa (UFV), buscou-se a promoção do projeto de extensão "Outras janelas para o mundo - A leitura e a escrita como arte e como prática libertadora", que ocorreu de $1^{\circ}$ de fevereiro de 2015 a 31 de dezembro de 2015, em parceria com a Universidade e com outros servidores dessa Instituição, com o objetivo de intervir nessa situação para que tanto a leitura quanto a escrita possam realmente atuar como fator de intervenção social.

Por meio da análise da realidade de vida das crianças e jovens envolvidos, o Projeto realizou, a partir desse contexto, atividades que pudessem desenvolver o hábito da leitura e despertar a criatividade e o interesse pela produção oral e escrita com a finalidade de promover a reflexão e a capacidade crítica, criadora e transformadora do meio social ao qual esses jovens estavam inseridos.

A princípio, o Projeto foi desenvolvido na Associação Comunitária Padre Geraldo Paiva em Viçosa, MG. A presidente da Associação tem um histórico de trabalhos sociais visando à recuperação e à reintegração social de dependentes químicos. Já atuou, também, como representante comunitária e decidiu criar uma casa que acolhia cerca de 40 crianças e adolescentes em idade entre 6 e 15 anos, oriundos de situações de desestrutura familiar, financeira, social e em área de risco; sendo que, muitas vezes, alguns desses problemas estão relacionados ao fato de que muitas das famílias envolvidas já tiveram, ou ainda têm, pessoas em situação de dependência química.

Esse acolhimento era realizado no horário alternativo da escola, oferecendo a essas crianças e jovens a oportunidade de convivência afetiva equilibrada e saudável, visando seu pleno desenvolvimento; pois, na referida Associação, as crianças e adolescentes recebiam não apenas um abrigo, mas também assistências de vários níveis, como psicológica e pedagógica; entre elas as atividades de informática, música, reforço escolar, esporte e lazer.

As mães e irmãs desses jovens também participavam de algumas oficinas como as de cabeleireiro e manicure. Crianças e adolescentes eram convidadas a visitarem a instituição e a participarem das atividades, que tinham como princípio básico a formação do sujeito autônomo e crítico, o fortalecimento da autoestima dos meninos e meninas e o apoio na construção de seus projetos de vida. Para tanto, a Associação contava com doações de roupas, material escolar, livros e alimentos numa participação interativa da comunidade na qual muitos atuam como voluntários.

Porém, a ACPGP mudou-se em junho de 2015 para outro endereço. Por isso, os(as) assistidos(as) desistiram de frequentar a Associação, uma vez que ela ficava longe de suas residências. Sendo assim, o Projeto precisou ser transferido, em agosto de 2015, da ACPGP para a "Casa de Acolhimento Esperança do Amanhecer", coordenado pelo Consórcio Intermunicipal de Atendimento à Criança e ao Adolescente (CIACA), também em Viçosa.

O CIACA atende crianças de 0 a 18 anos, vindas de famílias em situação de risco. É instalada em um amplo imóvel, com escritório de administração, biblioteca, dormitórios masculinos e femininos, 
berçário, área de estar, refeitório, cozinha e grande área de lazer ao ar livre. Além de ser uma casa para abrigo de crianças e adolescentes em situação de risco, o CIACA oferece uma grande prestação de serviços e cuidados primorosos aos seus residentes: escola, transporte escolar, atendimento médico e odontológico, assistência pedagógica, além da participação em todos os projetos sociais que têm parceria com a Prefeitura.

Assim, o Projeto "Outras janelas para o mundo - A leitura e a escrita como arte e como prática libertadora" buscou intervir positivamente na realidade de ambas instituições, trabalhando a habilidade de compreensão e de interpretação a fim de que as crianças e jovens pudessem reconhecer o poder da palavra. Por isso, o trabalho teve a função de desenvolver uma maior autonomia na capacidade de comunicação e de expressão dos jovens a fim de se garantir uma postura crítica e transformadora diante do conhecimento para uma aprendizagem efetiva e significativa como instrumento de formação humanística e crítica, de intervenção social e, consequentemente, de melhoria da qualidade de vida de toda a sociedade.

\section{Referencial teórico}

Essa perspectiva de desenvolvimento das capacidades de leitura e de escrita provoca a constituição de um pensamento crítico e reflexivo, o que colabora, claramente, para a inclusão social. Entretanto, foi necessário que esse trabalho se realizasse a partir de um planejamento baseado num estudo inicial da realidade de vida das crianças e jovens das referidas Associações.

Porém, como afirma Pimenta e Lima (2004, p. 67), “o diagnóstico não se limita a uma visão inicial, mas se realiza como processo permanente de identificação das necessidades e possibilidades que permitam rever ou reafirmar as opções, uma vez que a realidade é dinâmica, viva, mutável." Sendo assim, é importante ressaltar que a apropriação desses dados foi necessária, mas se deu também de maneira contínua, já que o verdadeiro diagnóstico da realidade vai muito além dos dados quantitativos, pois envolve, principalmente, as situações de vida como condição social, econômica e religiosa desses jovens, bem como seus interesses, influenciados ou não pelas informações que eles recebem de várias formas, principalmente, pelo acesso à mídia.

Segundo Libâneo (2004), o diagnóstico, realizado a partir da coleta de dados, busca analisar e explicar uma situação, porém precisa ser articulado com suas causas internas e externas. A partir desse trabalho, foi possível e necessário um replanejamento e, também, uma reconsideração das ações, mantendo-se a atenção às reavaliações, que conduziram a novas propostas e, assim, sucessivamente.

Tudo isso para que fosse possível realizar um trabalho fundamentado na ideia de que a palavra possui papel fundamental, pois é a partir dela que o sujeito se constitui e é constituído (BAKHTIN, 2003). Nessa concepção, o desenvolvimento das habilidades de ler, compreender, interpretar e produzir textos é de grande importância, uma vez que confere possibilidades de acesso ao mundo letrado e, portanto, de exercício da cidadania, promovendo formas de participação e de integração do indivíduo ao tecido sociocultural simultaneamente.

Dentro dessa concepção, percebe-se a importância da leitura como instante crítico da constituição do texto, ao mesmo tempo em que o leitor real encontra um leitor virtual já constituído no texto (ORLANDI, 2001b, p. 186); pois, a relação de interação do e no próprio texto, faz com que ele se constitua um espaço aberto e nunca fechado em si mesmo.

Essa visão do ler e do escrever teve um impacto direto na fundamentação das atividades deste trabalho, visto que a palavra só passa a ser significativa quando é apropriada por alguém que é capaz de transmiti-la a outro, que deverá, por sua vez, ser capaz de compreendê-la. Por si mesma, nada ela pode fazer conhecer, já que, segundo Bakhtin, a linguagem deve ser vista como um instrumento de interação humana, pois ela ocupa posição central nas relações sociais e não apenas serve de instrumento nas nossas interações como pode ser capaz de (re)construir nosso sistema social, cultural e histórico.

Ademais, segundo Kock (1989, p. 19), o texto é a unidade básica de manifestação da linguagem e [...] é muito mais que uma soma das frases (e palavras) que o compõem: a diferença entre frase e texto não é meramente de ordem quantitativa; é, sim, de ordem qualitativa. Isso justifica o fato de que o presente projeto teve os textos escritos ou orais como principal ferramenta de ação.

A despeito de tudo isso, é indiscutível o preconceito, por parte de crianças, jovens e adultos, em relação à atividade de leitura e ainda mais à de produção de textos, que é vista por eles como "dom" 
ou como capacidade provinda de "inspiração divina". Para vencer essa visão, culturalmente, antiquada e inadequada, é preciso entender que correspondem a uma atividade muito mais laborativa do que se imagina erroneamente. Mattoso Câmara (2001, p. 58) diz que "qualquer um de nós senhor de um assunto é, em princípio, capaz de escrever sobre ele. Não há um jeito especial para a redação, ao contrário do que muita gente pensa. Há apenas uma falta de preparação inicial, que o esforço e a prática vencem".

O pior ainda acontece quando a leitura é imposta ou, como relata Geraldi (1995, p. 65), "a produção de textos na escola foge totalmente ao sentido de uso da língua: os alunos escrevem para o professor (único leitor quando lê os textos). A situação da língua é, pois, artificial".

Tendo isso em vista, torna-se indiscutível, portanto, a importância do ensino/aprendizagem de leitura e produção de texto como forma de inclusão social a partir da perspectiva de que essa prática deve partir do interesse das crianças e jovens. Esse interesse também deve estar relacionado as suas realidades e deve ser trabalhado por meio de atividades interessantes e diversificadas que constituam um desafio à criatividade e ao desempenho, formando leitores e escritores capazes de entenderem o que leem e de se expressarem de forma consciente e crítica, pois o eixo de estrutura do ensino da língua deve ser sempre a ação social.

Para tanto, justifica-se uma intervenção que corrobore para essa ressignificação das práticas de leitura e escrita a partir do princípio de que o indivíduo age no e sobre o mundo, por meio delas em todas as situações, o tempo todo e em qualquer lugar. Isso requer a conciliação de instituições colaboradoras além da parceria de técnicos e docentes, bem como da comunidade em geral no sentido de se extrapolar o tempo e o espaço em relação à linguagem.

Diante do exposto, observa-se que a relevância social deste Projeto consistiu em despertar nos estudantes o hábito da leitura e apresentar a produção criativa de textos como algo prazeroso e necessário para a formação do cidadão; além de se propor um espaço de reflexão para toda a comunidade participante no sentido de lembrar que todos podem colaborar nesse processo e de que todos poderão usufruir de seus resultados, como afirma Paulo Freire (1997 p. 27):

É que não existe ensinar sem aprender e com isto eu quero dizer mais do que diria se dissesse que o ato de ensinar exige a existência de quem ensina e de quem aprende. Quero dizer que ensinar e aprender se vão dando de tal maneira que quem ensina aprende, de um lado, porque reconhece um conhecimento antes aprendido e, de outro, porque, observando a maneira como a curiosidade do aluno aprendiz trabalha para apreender o ensinando-se, sem o que não o aprende, o ensinante se ajuda a descobrir incertezas, acertos, equívocos. E aqui devemos ser todos sujeitos, solidários nesta tarefa conjunta, único caminho para a construção de uma sociedade na qual não existirão mais exploradores e explorados, dominantes doando sua palavra opressora a dominados.

\section{Objetivos}

Não é difícil perceber uma grande defasagem das crianças e jovens nas habilidades de leitura, compreensão, interpretação e produção criativa de textos, nem que esse problema não se trata de uma situação isolada, mas de um obstáculo a ser transposto por muitos na sociedade em função de uma análise antiga e conservadora da linguagem de grande parte da sociedade, assim como do ambiente escolar.

O Projeto, portanto, buscou atender algumas das metas do Plano Nacional de Extensão Universitária no sentido de realizar o trabalho de troca de saberes sistematizados, acadêmicos e populares, a prestação de serviços, a difusão cultural e a colaboração em atividades que pudessem, de alguma forma, propiciar a sensibilização dessas crianças, desses jovens e de suas famílias de seus papéis como cidadãos para que possam atuar na sociedade na condição de sujeitos.

Com o projeto, almejou-se oportunizar aos jovens a sugestão de inúmeras obras literárias de variados autores, ampliando seus conhecimentos e suas capacidades criativas; proporcionar situações sociais de leitura, de discussões sobre obras lidas e de indicação das apreciadas, além de selecionar estratégias de leitura conforme os propósitos específicos; desenvolver a capacidade de interpretação oral e escrita, articulando variadas áreas do conhecimento. Ainda teve como meta realizar atividades que possibilitassem identificar recursos linguísticos, procedimentos e estratégias discursivas para relacionálas com seu gênero e aplicá-las à produção criativa de textos literários, argumentativos e poéticos. 
Ademais, procurou-se estimular a produção de textos em diferentes gêneros promovendo o desenvolvimento da escrita e da criatividade para contar e recontar, produzir e reproduzir histórias; debater temas contemporâneos, também com a contribuição dos textos de gêneros variados, ao se expor dúvidas e dificuldades, buscando, em conjunto, encontrar soluções e novos caminhos. O objetivo principal foi desenvolver uma consciência crítica e política que defendesse a equidade de gênero, a inclusão social, a constituição da cidadania; a valorização do artístico, a capacidade de compreensão, de interpretação e de expressão, a socialização e a autonomia, a criatividade, a lúdico, a corporeidade; além de apresentar a produção de textos (produto de trabalho, esforço e técnica) como ferramenta de ação social.

O Projeto consistiu, ainda, ao longo de 2015, em oferecer oficinas de teatro realizado por uma professora da UFV formada em Artes Cênicas (colaboradora) e o apoio pedagógico ao trabalho de reforço escolar, realizado por uma pedagoga da UFV (colaboradora).

Sendo assim, este Projeto intencionou oferecer a oportunidade de um outro olhar sobre a linguagem, assim como outra visão sobre o ensino de leitura e de escrita como instrumento de libertação e de construção de própria história. Afinal, a universidade não se deve posicionar como uma entidade da sociedade, mas como parte dela.

Ademais, o Projeto procurou desvendar a carência efetiva nas capacidades de compreensão e de expressão dos estudantes, socializando o saber produzido e acumulado de forma a intervir positivamente no desenvolvimento desses educandos e promovendo o resgate da cidadania por meio do ato de ler, com a possibilidade de se compreender e de se interpretar o que foi lido, e por meio do ato de escrever, para que essas crianças e jovens possam se descobrir capazes de expressar suas concepções e suas visões de mundo por intermédio de eventos diversos de leitura e escrita.

\section{Metodologia e ações participativas}

O Projeto se divide em 3 (três) eixos centrais, sendo que alguns deles foram colocados em prática simultaneamente.

\section{Primeiro eixo: Apresentação do Projeto e fase diagnóstica}

Para o planejamento das atividades foram realizadas reuniões entre a equipe (coordenadora, bolsista, servidoras colaboradoras e presidente da ACPGP e, posteriormente, do CIACA) para apresentação formal do Projeto, para debates, análise e sugestão de bibliografia pertinente e propostas de atividades.

Realizou-se, de início, a elaboração de um diagnóstico que compreendeu uma análise da estrutura e do funcionamento do local onde se realizariam as atividades, da realidade de vida, do meio social e das famílias das crianças e dos jovens, por meio de visitas à Associação atendida pelo Projeto, às famílias e à comunidade desses jovens, além de conversas informais com esses envolvidos a fim de se conhecer efetivamente a comunidade à qual o Projeto se direciona e os fatores causadores de um possível desinteresse pela leitura e pela escrita, a fim de melhor intervir positivamente ali.

Sobre o trabalho diagnóstico, cabe ressaltar que, tanto na ACPGP, quanto no CIACA, foi preparado um questionário com algumas perguntas para que a bolsista e toda a equipe do projeto pudessem conhecer tanto a instituição quanto os(as) assistidos(as), trabalhando dados como: nome, religião, idade, série escolar, nome da escola, o que gosta de ler, fazer, brincar, dançar, escrever, assistir, desenhar, o que pensa em ser no futuro (profissão) e por que ia à associação.

A parte principal da pesquisa diagnóstica foi realizada, quando na ACPGP, durante as tardes, no período de fevereiro e março e a bolsista foi acompanhada da Presidente da Associação na busca de novos participantes para o projeto. Quando no CIACA, a entrevista com os(as) assistidos(as) foi realizada na própria instituição e na companhia da Administradora. Durante todas as etapas de realização do Projeto esses dados foram atualizados.

\section{Segundo eixo: Replanejamento das atividades e dos recursos a serem utilizados}

A partir das visitas à comunidade e às Associações; a partir das conversas com as famílias das crianças e dos relatórios produzidos a respeito da realidade constatada, foi estabelecida uma base para um replanejamento das metas e para uma readaptação das atividades e das metodologias já 
propostas no Projeto.

Dessa forma, foi possível, por meio da atividade diagnóstica, planejar atividades que pudessem intervir positivamente no desinteresse pelas práticas de leitura e produção textual, incentivando a criatividade, visando desenvolver as potencialidades de comunicação, o prazer de ouvir e de fazer; atividades ainda que oportunizassem aos jovens uma sugestão de inúmeras obras literárias de variados autores, com o objetivo de ampliar seus conhecimentos e que trabalhassem a leitura como fonte essencial para produção textos.

Além disso, foram pesquisadas e planejadas atividades que pudessem proporcionar situações sociais de leitura, de discussões sobre obras lidas e de indicação das apreciadas; selecionar estratégias de leitura conforme os propósitos específicos; desenvolver a capacidade de compreensão e de produção de texto oral e escrito, com a articulação de várias áreas do conhecimento.

\section{Terceiro eixo: Oficinas, contato com a comunidade e prestação de serviços, exposição de} trabalhos

Foram formadas 02 turmas pequenas para as oficinas, sendo que uma delas se realizaria sempre pela manhã e a outra pela tarde para que todos os jovens e crianças pudessem participar e, também, de modo que a bolsista conseguisse dar assistência individualizada em atividades como debates, produção textual, correção e reescrita dos textos Foram aindaescolhidos o espaço físico e os horários de funcionamento das atividades, de forma adaptada à disponibilidade da Associação atendida e dos interessados em participar, já que as oficinas ocorreram uma vez por semana, tinham a duração de 4 horas cada e eram divididas entre os variados tipos de atividades e objetivos.

As 20 horas semanais dedicadas ao projeto foram destinadas a reuniões da bolsista com a coordenadora e/ou com os demais colaboradores, à pesquisa e ao estudo individuais, às atividades diagnósticas (como visitas à Associação, às comunidades dos jovens e encontros com as famílias deles) e às oficinas das atividades propostas.

Foram realizadas oficinas de leitura silenciosa, oral, individual, em grupo e dramatizada; análise, interpretação e compreensão de texto de forma escrita, oral e em grupo; além de produção textual, debates e oficinas de teatro e de representação artística com o auxílio da bolsista.

O estímulo à leitura e à escrita realizado por este Projeto se baseou nos seguintes tópicos:

- Apresentação da bolsista sempre como leitora, atualizada, participante, seduzida pela leitura e mostrando a importância da leitura no desenvolvimento crítico e criativo das crianças e jovens participantes;

- Formação do hábito da leitura/escrita a partir da seleção de material, que deveria incluir informação e recreação, em vez de ser imposto como obrigação;

- Articulação das diferentes situações de leitura: silenciosa, oral, em grupo e individual;

- Ressignificação da atividade de leitura/escrita para os participantes, correspondendo sempre a uma finalidade que eles pudessem compreender e partindo sempre dos conhecimentos prévios dos envolvidos;

- Trabalho com uma grande variedade de gêneros textuais;

- Relacionamento das atividades de leitura e escrita às relações afetivas e às situações práticas;

- Organização do acervo realizada pelos próprios participantes e disponibilização diversos tipos de texto;

- Manutenção da biblioteca/cantinho de leitura/escrita sempre que possível de portas abertas, com acesso livre aos leitores/escritores estimulando assim a curiosidade e o interesse individual deles;

- Planejamento cuidadoso das atividades de leitura e de escrita, evitando-se a concorrência entre os participantes, com o objetivo de ressaltar que cada um deveria avançar em seu próprio ritmo, construindo sua própria interpretação.

Os recursos financeiros para essas atividades foram obtidos por meio de doações e as reuniões semanais tiveram o objetivo de avaliar o trabalho realizado, planejar e orientar as atividades das próximas semanas, além de formar um banco de atividades, com textos variados para todos os tipos de oficinas a serem realizadas.

Além disso, a equipe do Projeto manteve contato frequente via internet, sempre que se fizesse necessário. 
Destacam-se, ainda, as seguintes atividades realizadas:

- Incentivo ao hábito de leitura por meio de atividades motivadoras de leitura (como, por exemplo, roda de leitura e contação de histórias) e de campanha de arrecadação de livros e gibis para o acervo do Projeto.

- Leitura de textos (individual e/ou em grupo) e produção de textos de temas e gêneros variados.

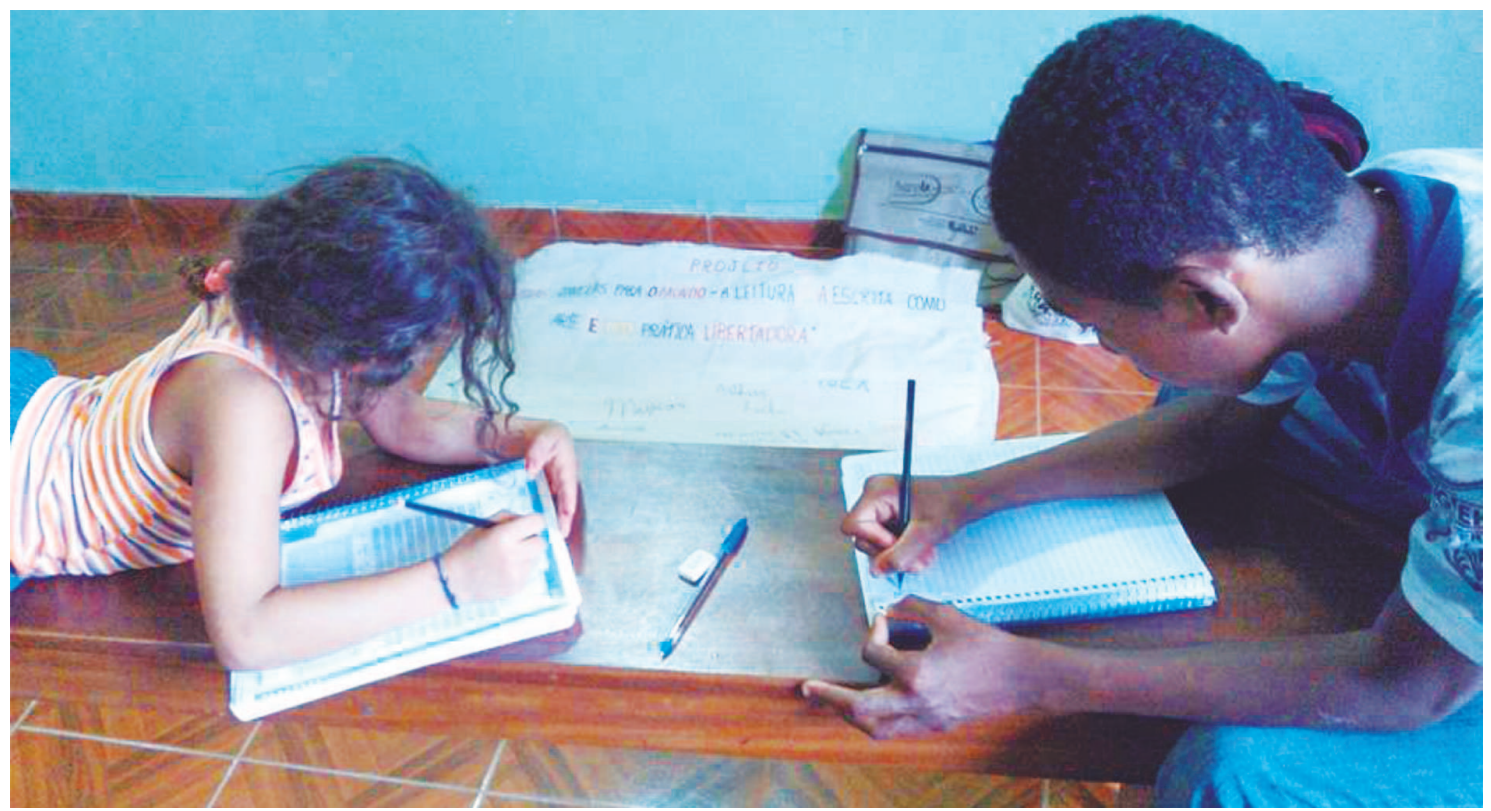

Figura 1 - Produção de textos de temas e gêneros variados no CIACA.

Fonte: Foto de Maria de Fátima dos Santos (bolsista do Projeto).

- Debates realizados a partir da leitura de textos sobre temas contemporâneos, envolvendo os jovens e trabalhadores da Associação, as famílias desses jovens e os membros do Projeto com o objetivo de propor ações capazes de transformar o meio social e as condições de vidas de toda a comunidade.

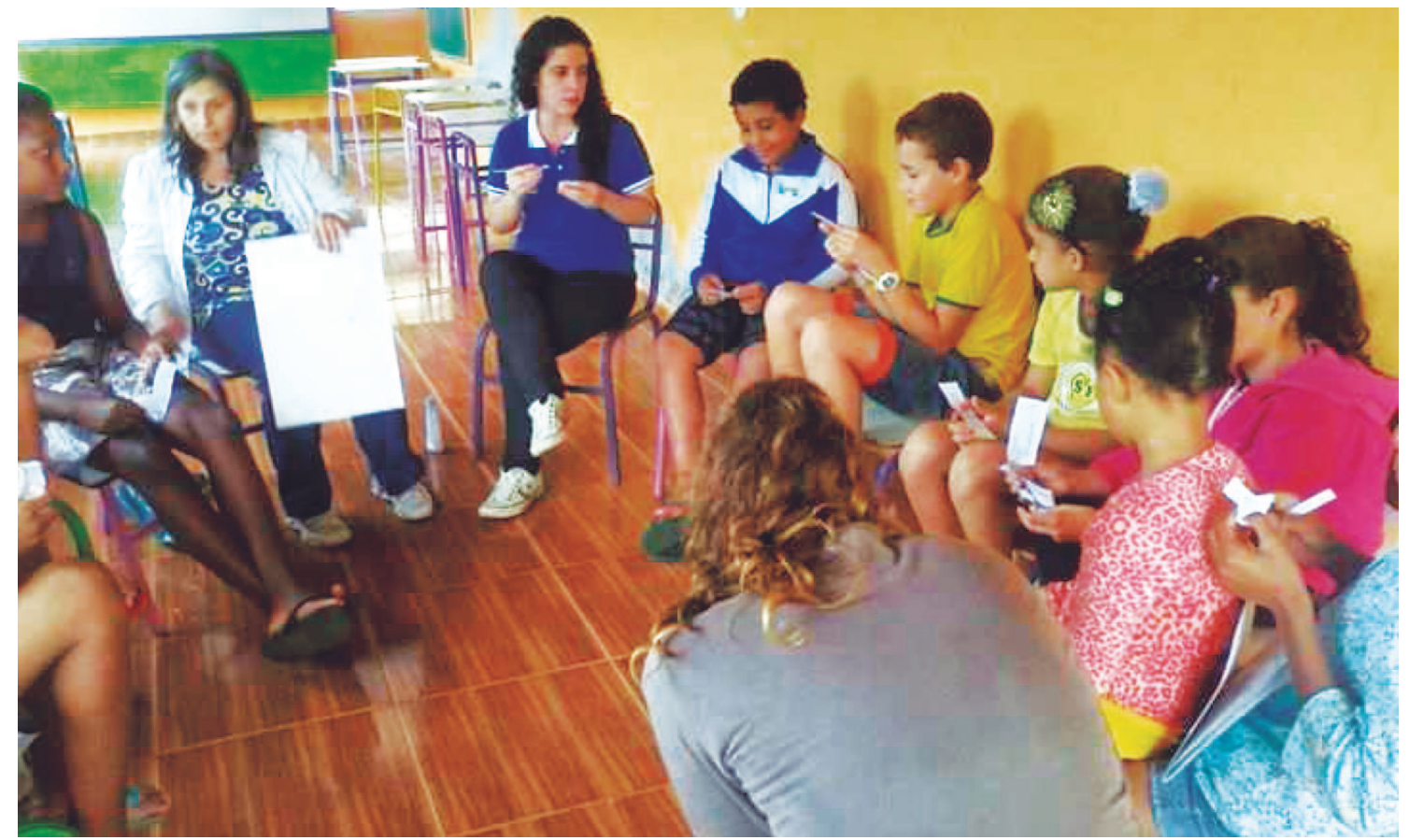

Figura 2 - Debates a partir da leitura de textos sobre temas contemporâneos no ACPGP Fonte: Foto de Maria de Fátima dos Santos (bolsista do Projeto). 


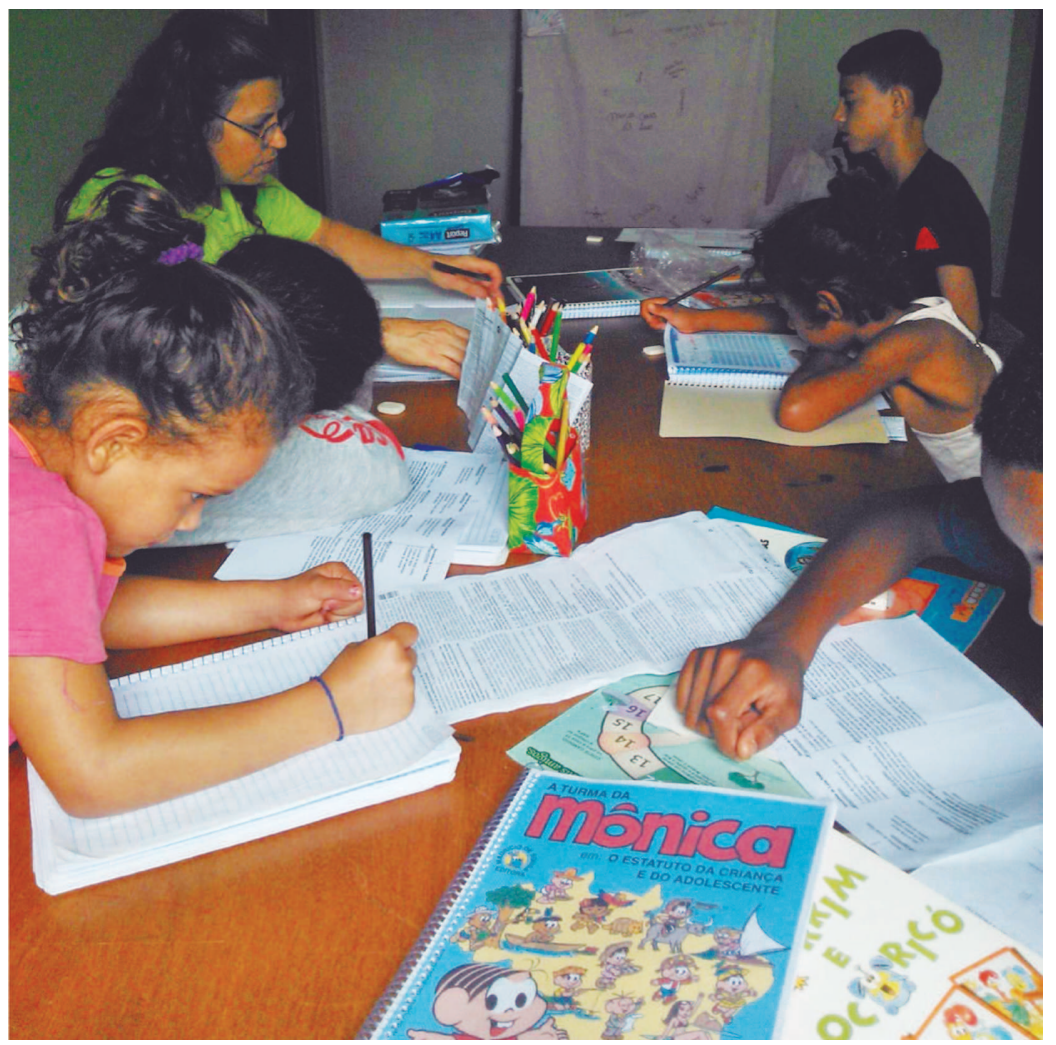

Figura 3 - Debate e produção textual a partir da leitura de O Estatuto da Criança e do Adolescente no CIACA. Fonte: Foto de Maria de Fátima dos Santos (bolsista do Projeto).

- Exibição de filmes e atividades de compreensão e interpretação de texto fílmico.

- Criação do cantinho da leitura de maneira organizada e acolhedora, de forma a proporcionar condições para despertar o interesse dos estudantes pela leitura, facilitando, dessa forma, também, a apropriação do conhecimento.

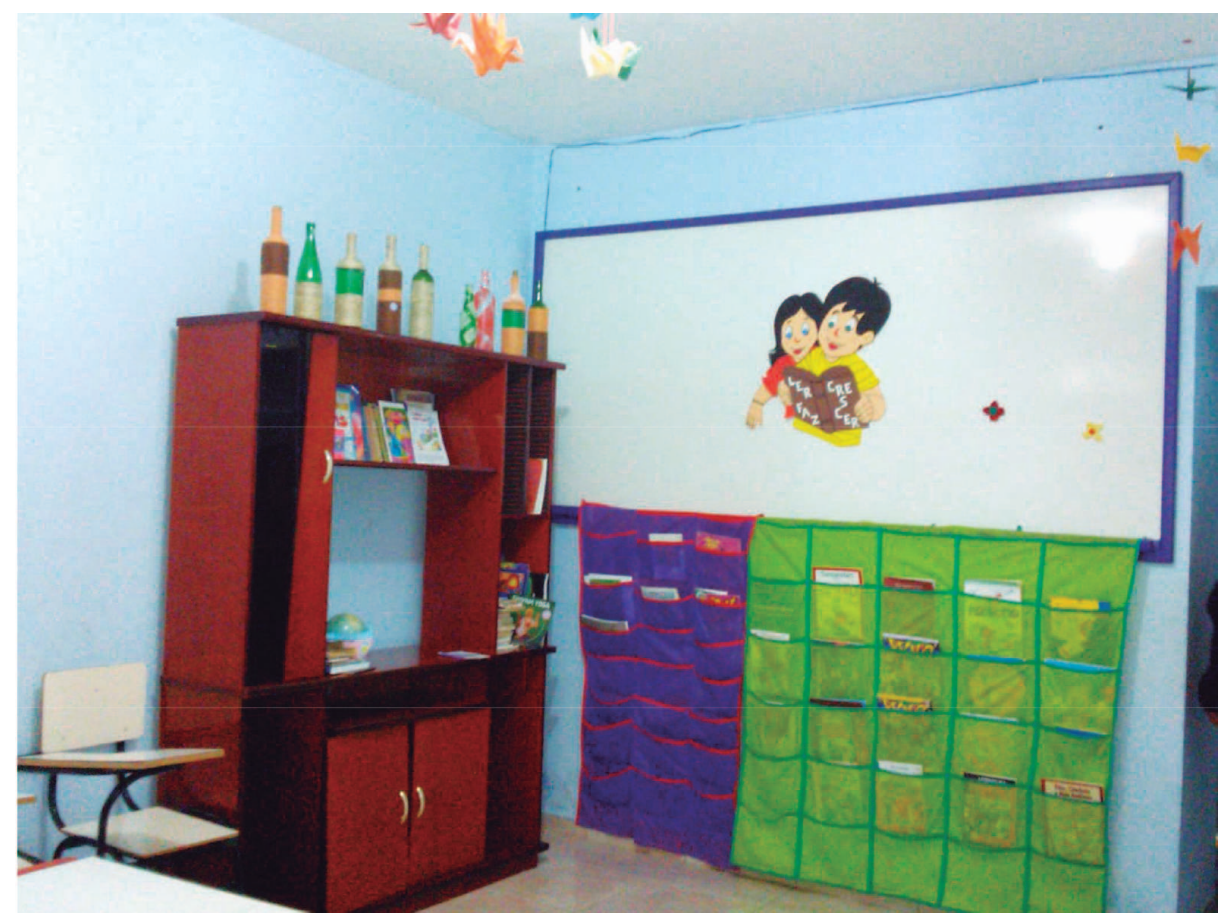

Figura 4 - Cantinho de leitura na ACPGP.

Fonte: Foto de Maria de Fátima dos Santos (bolsista do Projeto). 
- Instituição de horários de leitura, dramatização ou representação artística em forma de teatro, desenho e pintura sobre a história lida ou ouvida e brincadeira de adivinhações.

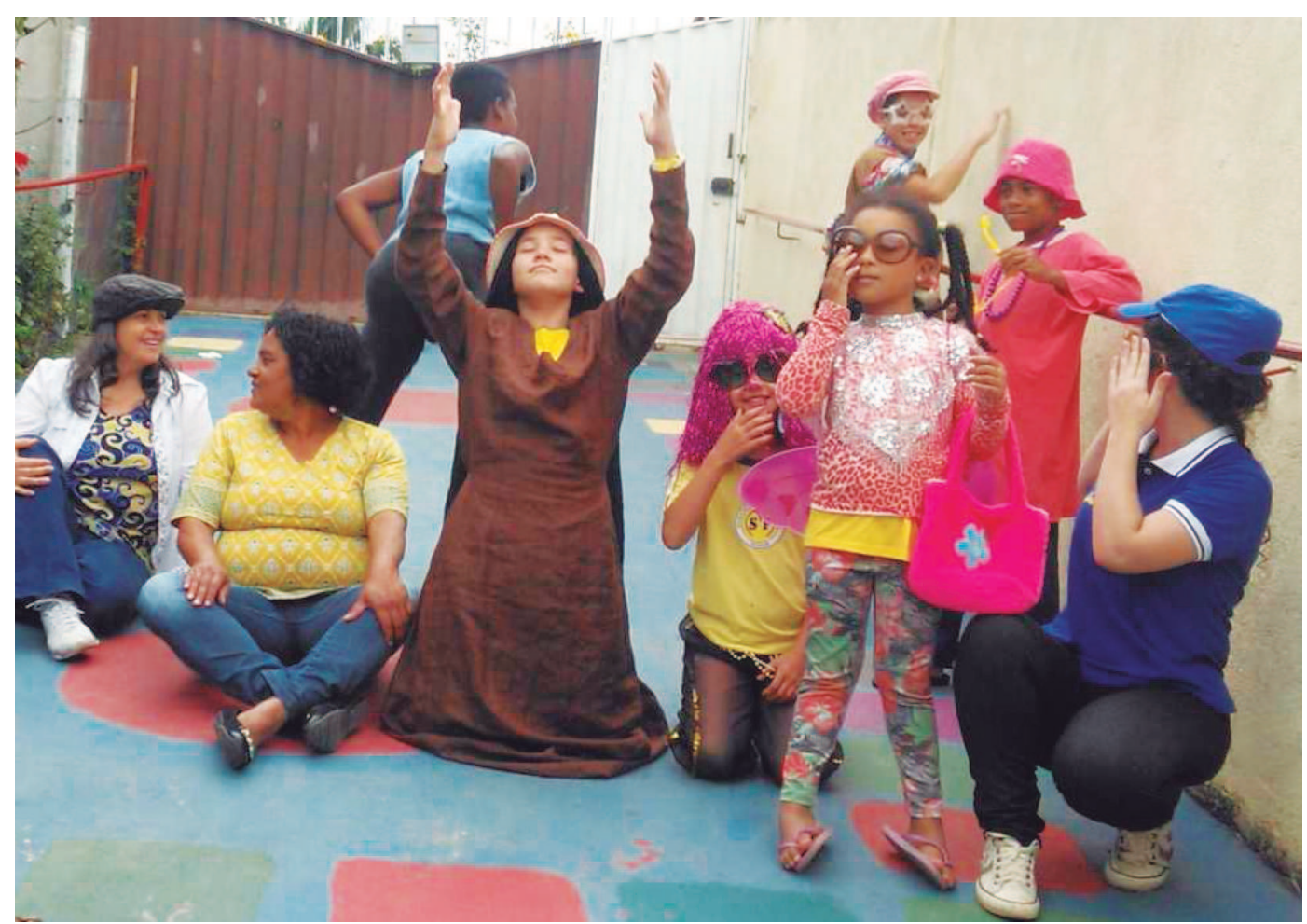

Figura 5 - Representação artística de livro lido na ACPGP. Fonte: Foto de Maria de Fátima dos Santos (bolsista do Projeto).

- Oficina de teatro; criação de textos para teatro, contação de histórias com fantoches, atividades de "Explosão de ideias", imitações de personagens proporcionando a oportunidade de que o(a) participante possa se ver no mundo da história como coadjuvante e não apenas como telespectador.

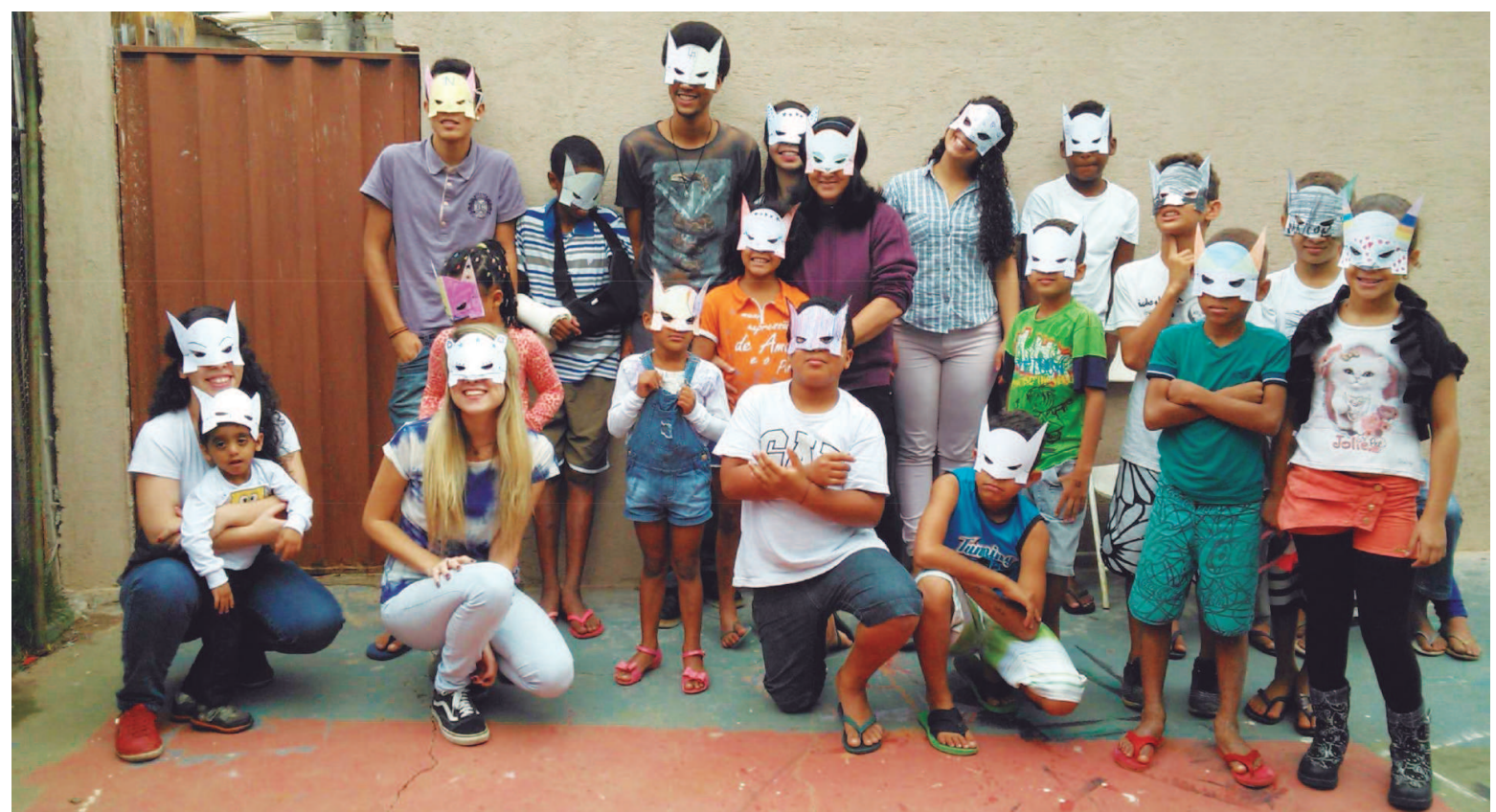

Figura 6 - Contação de histórias na ACPGP.

Fonte: Foto de Maria de Fátima dos Santos (bolsista do Projeto). 
- Leitura, análise, comparação e criação de poesias; álbuns de poemas, versos e trava línguas; produção de letras de música; confecção de murais e cartazes que servissem de divulgação dos textos e livros lidos ou produzidos.

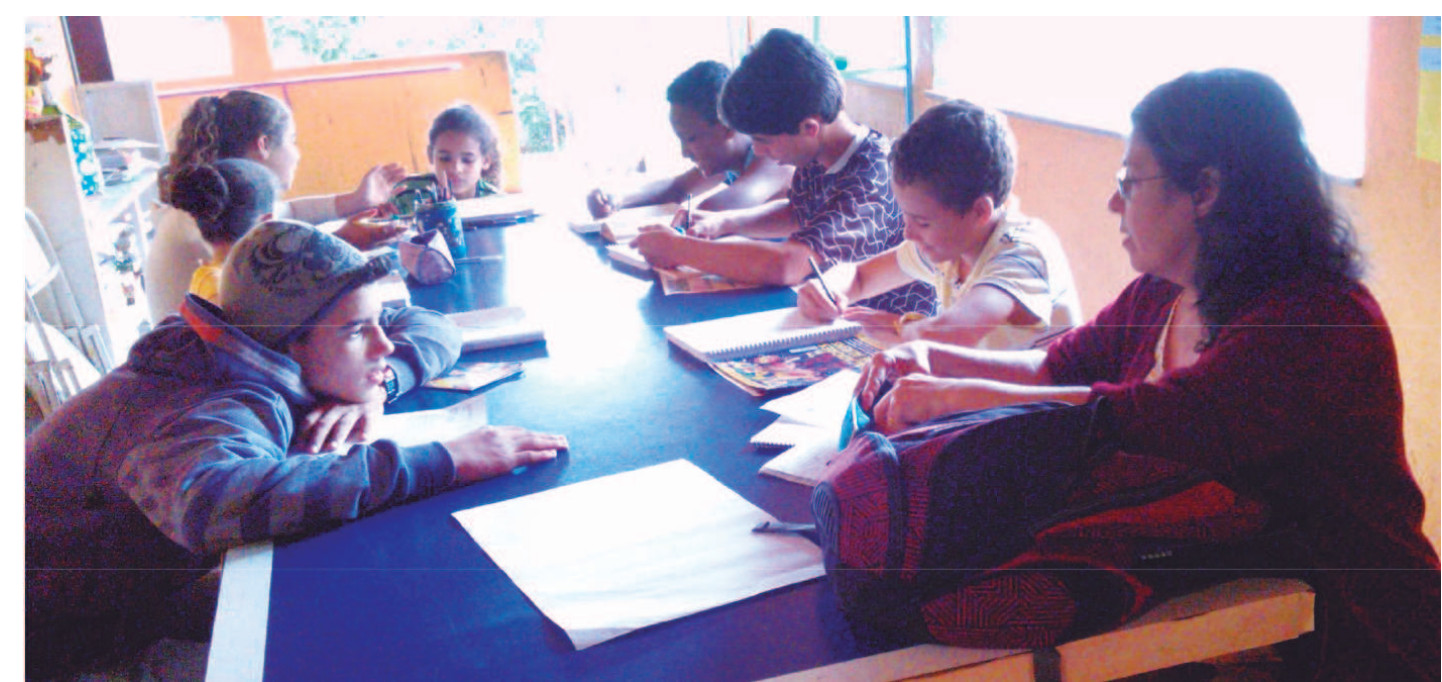

Figura 7 - Criação de poesias no ACPGP.

Fonte: Foto de Maria de Fátima dos Santos (bolsista do Projeto).

- Montagem e divulgação de uma exposição do material produzido pelos estudantes no Projeto a ser apresentado aos próprios participantes.

Parte essencial da metodologia são o acompanhamento e a avaliação dos trabalhos. Portanto, nos encontros e nos momentos de pesquisa e estudo em grupo e/ou individuais, foi possível discutir e refletir sobre textos e bibliografias a serem pesquisadas, relacionando teoria e prática. Dessa forma, a bolsista, a coordenadora e os colaboradores tiveram, a qualquer momento, a oportunidade de replanejamento, de reavaliação das atividades propostas e de apresentação de novas propostas de ações que viabilizassem o trabalho de incentivo à leitura e à escrita.

Foi realizada, também, uma avaliação contínua, durante toda a execução do Projeto, num processo de investigação, por meio de análise dos resultados obtidos, do comportamento, da capacidade e da qualidade de expressão dos estudantes, com o objetivo de verificar os efeitos das atividades propostas.

Ainda foi considerado, como fator de avaliação, o interesse de cada um dos envolvidos no Projeto na participação, na execução, na organização, na apresentação e na clareza da execução das atividades propostas, tanto individuais quanto coletivas, com base nas noções e conceitos construídos ao longo do projeto, bem como uma análise constante dos trabalhos realizados, dos relatórios produzidos e de um encontro bimestral entre o coordenador, os colaboradores, a bolsista e as presidentes das Associações, no qual se fazia uma análise comparativa entre o ponto de partida e aquilo que havia sido realizado até aquela etapa. Dessa forma, buscou-se intervir, intensificando, adequando ou alterando as ações.

Houve também o preenchimento periódico, por parte da coordenadora e da equipe do Projeto, de relatórios das atividades desenvolvidas pela bolsista, permitindo constatar, por meio da análise de dados obtidos no processo, seu desempenho até aquele período contendo os seguintes fatores de avaliação:

- Capacidade de realização das tarefas propostas;

- Proatividade e interação com a equipe;

- Assiduidade;

- Dedicação e Interesse;

- Iniciativa e Autonomia;

- Criatividade e Produtividade.

Nessa avaliação, houve sempre um conselho (formado por mais de um membro da equipe) para essa análise e para a reflexão sobre esses resultados. 


\section{Resultados}

O Projeto foi gratificante por constatar que é possível oferecer condições de aquisição do hábito da leitura e da produção escrita por parte de crianças e jovens inseridas em qualquer contexto social, por mostrar a todos a importância desse trabalho na vida de cada um e por possibilitar a todos os envolvidos a verificação do progresso individual e coletivo no desenvolvimento dos participantes por meio da leitura e da escrita.

Também observou-se que é possível realizar um trabalho que desperte nas crianças e adolescentes o interesse e o hábito da leitura, a criatividade, que promova espaços de reflexão sobre seus direitos e deveres e sobre a superação dos mais variados tipos de preconceitos e de exclusão por meio da capacidade de expressão e de compreensão do mundo; que obtenha o envolvimento dos familiares e da comunidade com a finalidade de levar os jovens a adotarem uma postura crítica e a se perceberem como potenciais transformadores do seu meio social e como agentes de desenvolvimento individual e coletivo.

Como resultado acadêmico, o trabalho de extensão realizado permitiu a parceria entre a bolsista, docentes, técnico-administrativos e a comunidade em geral em atividades que puderam criar espaço para estudo e para a ação, contribuindo para pesquisas, trabalhos e reflexões futuras; permitiu ainda a integração do saber prático e teórico, com o objetivo de construir conhecimento por meio da interação de todos.

Como resultado das atividades diagnósticas sobre a vida dessas crianças e jovens, percebeu-se quais fatores poderiam ser os causadores de possível desinteresse deles pela leitura e pela escrita. Esse estudo baseou-se nas reflexões de autores como Heathington (apud CRAMER e CASTLE, 2001, p. 230), que trata sobre a influência que a postura do professor por exercer sobre a formação do alunoleitor, que afirma que o hábito da leitura ou a falta deste pode e deve ser orientado e que deixa claro que são inúmeras as razões pelas quais uma criança ou jovem pode se tornar ou não um leitor efetivo; ou como Villardi (1997), que aborda a mesma questão quando afirma que, à medida que os alunos avançam na escolaridade, menor é a ligação que têm com a leitura. $O$ autor destaca assim que é como se os procedimentos pedagógicos adotados, em vez de aproximar os estudantes, fossem, aos poucos, afastando-os dos livros, criando entre eles uma relação de enfado e desinteresse (1997, p. 4). Constatouse, portanto, com essa pesquisa, de forma ética e responsável, que o ambiente físico, assim como o familiar, de pouca ou nenhuma estrutura, além da falta de equilíbrio nas relações interpessoais no qual eles estão inseridos influencia negativamente sobre a deficiência na capacidade de leitura e de expressão. Também foi possível perceber que muitas das crianças e jovens participantes do Projeto não tinham solidificado verdadeiramente a alfabetização, o que pode ter provocado uma frustração diante da educação formal, que impacta no processo evolutivo de aprendizagem, fazendo com que eles(as) apresentem baixo rendimento escolar e, aos poucos, baixa autoestima e desinteresse. Esse processo pode fazer com que eles(as) passem a escrever cada vez menos, tendo a criatividade e o imaginário limitados. Além disso, o pouco ou nenhum estímulo, assim como a falta de habilidade para perceber as possíveis deficiências por parte da família ou dos(as) professores(as) interfere diretamente na possibilidade de diagnóstico e de intervenção preventivos.

Traçando, dessa forma, um perfil da situação, foram propostos novos caminhos que pudessem estimular e incentivar essas crianças e jovens, aumentando a sua autoestima, a fim de se viabilizar uma postura crítica e consciente deles diante da sociedade e da construção de saberes, contribuindo, dessa forma, para o desenvolvimento integral dos participantes.

Afinal, só assim, é possível entender como as atividades de pesquisa, ensino e extensão podem contribuir para que se possa seguir por novos rumos a fim de se superar os mais variados tipos de preconceitos e de exclusão por meio da capacidade de expressão e da compreensão do mundo; obtendo o envolvimento dos familiares e da comunidade com a finalidade de levar os jovens e as crianças a adotarem uma postura crítica, a se perceberem como potenciais transformadores do seu meio social e como agentes de desenvolvimento individual e coletivo.

\section{Fonte de financiamento}

O Projeto "Outras janelas para o mundo - A leitura e a escrita como arte e como prática libertadora", recebeu o apoio da Universidade Federal de Viçosa/UFV pelo Programa Institucional de Bolsas de Extensão Universitária da Universidade Federal de Viçosa - PIBEX / UFV - 2015. 


\section{Agradecimentos}

A toda a equipe do Projeto, aos(às) colaboradores(as) das Instituições onde o Projeto se realizou, às crianças e aos jovens participantes do trabalho.

\section{Referências}

BAKHTIN, Mikhail. Estética da Criação Verbal. São Paulo: Martins Fontes, 2003.

BELINATNE, Claudemir. Leitura e alfabetização no Brasil: uma busca para além da polarização". in: Educação e Pesquisa, São Paulo, v.32, n.2, p. 261-277, maio/ago. 2006.

CAMARA JUNIOR, Joaquim Mattoso. Manual de expressão oral e escrita. 21. ed. Petrópolis, RJ: Vozes. 2001.

CRAMER, Eugene H.; CASTLE, Marrieta. Incentivando o amor pela leitura. Trad. Maria Cristina Monteiro. Porto Alegre: Artmed, 2001.

FARIA, Elaine Turk. “O professor e as novas tecnologias" in: ENRICONE, Délcia (Org.). Ser Professor. 4 ed. Porto Alegre: EDIPUCRS, 2004.

FÓRUM DE PRÓ-REITORES DE EXTENSÃO DAS UNIVERSIDADES PÚBLICAS BRASILEIRAS. Plano Nacional de Extensão Universitária. Ilhéus: Editus, 2001. (Coleção Extensão Universitária; v.1)

FREIRE, Paulo. Professora sim, tia não: cartas a quem ousa ensinar. $16^{\mathrm{a}}$ ed. São Paulo: Olho D'Água, 1997.

GERALDI, J. W. Portos de passagem. 3.ed., São Paulo: Martins Fontes, 1995.

KOCH, Ingedore Villaça. O texto e a construção dos sentidos. São Paulo: Contexto. 1997.

LIBÂNEO, J. C. Didática. São Paulo, Cortez, 1994.

NOGUEIRA, Maria das Dores Pimentel (org.). Extensão Universitária: diretrizes e políticas. Belo Horizonte: PROEX / UFMG, 2000.

ORLANDI, Eni Puccinelli. A linguagem e seu funcionamento: as formas do discurso. 4ed. Campinas, SP: Pontes, 2001b.

PANET, Carmem de Faria. Implantação e funcionamento de bibliotecas infanto-juvenil. 1998. 70 f. Dissertação (Mestrado em Biblioteconomia) - Centro de Ciências Humanas, Letras e Artes. Universidade Federal da Paraíba, João Pessoa.

PIMENTA, Selma Garrido; LIMA, Maria Socorro Lucena. Estágio e docência. São Paulo: Cortez, 2004. POLÍTICA DE EXTENSÃO DA UFV. RESOLUÇÃO No 7/2007 - CEPE. Disponível em <http:// www.ufv.br/soc/files/pag/cepe/completa/2007/07_07.htm> Acesso em: 20 de setembro de 2014.

VILLARDI, Raquel. Ensinando a gostar de ler e formando leitores para a vida inteira. Rio de Janeiro: Dunya, 1997.

Recebido para publicação em 26/4/2016 e aprovado em 19/9/2016. 